\title{
Socio-demographic Factors Associated with Utilization of Breast and Cervical Cancer Screening Methods in Turkey
}

\author{
(1) Duygu ÜREK, ${ }^{1}$ (i) Sevilay KARAMAN, ${ }^{2}$ (i) İpek BilgGiN, ${ }^{3}$ (i) Oğuz IŞIK, ${ }^{2}$ (i) Özgür UĞURLUOĞLU² \\ 'Department of Health Management, Karadeniz Technical University, Trabzon-Turkey \\ ${ }^{2}$ Department of Health Care Management, Hacettepe University, Ankara-Turkey \\ ${ }^{3}$ Department of Health Care Management, Istanbul Medeniyet University, İstanbul-Turkey
}

\begin{abstract}
OBJECTIVE
Early screening methods are very important in reducing morbidity and mortality, especially in breast cancer (BC) and cervical cancer (CC). This study aims to investigate the sociodemographic factors associated with utilization of $\mathrm{BC}$ and $\mathrm{CC}$ screening methods among women in Turkey.

\section{METHODS}

The data were used from the Turkey Health Survey conducted by Turkish Statistical Institute in 2014. We included 8606 women aged 25 and over in the study. The utilization of early screening methods (breast self-examination [BSE], mammography, or Pap smear [PS] test) was the dependent variable. Chi-square test was used to assess the association between sociodemographic factors and utilization of early screening methods.
\end{abstract}

\section{RESULTS}

As a result of the analysis, it was found that $46.5 \%$ of the women practiced BSE, $32.4 \%$ and $35.4 \%$ had mammography screening and PS test at least once, respectively. The results also indicated that there were statistically significant associations between sociodemographic factors such as age, marital status, education and income level, having chronic diseases, consulting a family physician, health status, and utilization of early screening methods.

\section{CONCLUSION}

Improving access to early screening methods is of great importance in reducing mortality and morbidity related to BC and CC. It is believed that certain enhancements, such as increasing women's awareness about cancer screening, should become widespread to increase the number of women using these methods.

Keywords: Breast cancer; cervical cancer; screening methods; Turkey.

Copyright $\odot$ 2022, Turkish Society for Radiation Oncology

\section{Introduction}

Cancer, which is expected to cause 24.1 million new cases and 13 million deaths by 2040, is an important public health problem worldwide, including Turkey. Among cancer types, breast cancer (BC) is the most common cancer in women in almost all countries worldwide. In 2018, approximately 2.1 million new cases and 630,000 deaths occurred due to BC. With about 570,000 new cases and 312,000 deaths reported in 2018, cervical cancer (CC) is the fourth most common cancer among women worldwide. In Turkey, BC, which is the most common female cancer type, constitutes $24.4 \%$ of cancers. The age-standardized incidence rate of $\mathrm{BC}$ is estimated to be 45.6 (per 100,000) in 2018.[1] CC is the $13^{\text {th }}$ most common cancer 
type among women for all age ranges and fourth for women aged 15-44 in Turkey. The age-standardized incidence rate of CC is estimated to be 4.8 in 2018 (per 100,000).[2]

Early screening methods are particularly effective in reducing morbidity and mortality associated with these two cancer types.[3,4] According to the World Health Organization, [5] the only BC screening method that has proved to be effective is mammography screening (MS). Recommendations for MS vary by country. For example, while MS is recommended for women aged 40 and over every 1 or 2 years in Greece, it is recommended for women aged 50-74 every 2 years in Israel.[6] According to national standards in Turkey, MS is recommended for women aged 40-69 every 2 years.[7] However, population-wide implementation of MS is limited due to the lack of infrastructure and trained workforce in developing countries. Hence, breast self-examination (BSE) is advocated in view of its cost-effectiveness in these countries. [8] Although there are debates about BSE, it is still involved in screening programs in many countries.[9] For example, in Turkey, BSE is recommended for women since the 20s for raising awareness about their own health. [7] It is stated that the diagnosis of $\mathrm{BC}$ is much less common in women under the age of 40.[10] However, in Turkey, it is seen that $40.4 \%$ of women diagnosed with $\mathrm{BC}$ are between the ages of 25-49.[11] BC diagnosis in younger women can have a greater impact than older counterparts due to its tendency to appear at a later stage, to be more aggressive and have a worse prognosis.[10] Hence, younger women also need to practice BSE or perform MS in Turkey.

In the diagnosis of CC, Pap smear (PS) test is a commonly used cost-effective method.[12] There are different recommendations about when to start PS screening. For example, PS is recommended for women aged 25-65 every 3 years in France and Israel.[6] According to national standards in Turkey, PS is recommended for women aged 30-65 every 5 years.[7] On the other hand, many jurisdictions recommend that CC screenings begin when a woman becomes sexually active, regardless of age.[13] Considering that the mean age at first marriage is $25 \mathrm{~s}$ for women in Turkey,[14] it is also important to screen younger women.

Despite evidence that early screening methods reduces morbidity and mortality, BSE practice rates, mammography, and PS performing rates are quite low in Turkey.[15-17] In addition to determining the rates, it is also very important to identify related factors. The previous studies conducted for this purpose have in- vestigated the situation at a provincial level in Turkey. $[3,15,17]$ Not only to ascertain probable fields of intervention that may lead to an increase in screening rates but also to track down women across the country who insufficiently use these methods, it is of essential importance determining factors associated with the utilization of these methods.

\section{Materials and Methods}

\section{Study Design}

The aim of this study is to investigate the utilization of early diagnosis methods for BC and CC by women in Turkey based on several factors. In this context, the study investigates the BSE practice rates, mammography, and PS performing rates and further determines whether there is a difference in these rates with respect to several personal features. This study utilized data from Turkish Statistical Institute (TURKSTAT)'s[18] Turkey Health Survey 2014 by obtaining necessary permissions from the relevant institution. This study, which is a secondary analysis of the data from Turkey Health Survey 2014, does not require ethical approval for research on human/animal subjects.

Turkey Health Survey has been conducted by the TURKSTAT every 2 years since 2008 to ascertain the general health profile of the population. The geographical scope of the Turkey Health Survey 2014 constitutes all households residing in settlements within the borders of the Republic of Turkey. The soldiers, people who stay permanently in dormitories, prisons, hospitals, nursing homes, etc., were excluded. The sample size was calculated to do estimations on the base of total of Turkey and the required total sample size was found to be 9740 households. The survey was concluded with 8634 households out of 9740 households. TURKSTAT reached 26,075 individuals representing the entire population of the country by face-to-face interviews.[18] Although early screening methods are recommended for specific age groups, considering that approximately half of women diagnosed with BC are between the ages of 25 and 49[11] and the mean age at first marriage is 25s for women in Turkey,[14] we excluded male participants and women between 0 and 24 years of age. After excluding, the final sample of this research includes 8606 women aged 25 and over.

\section{Study Variables}

The dependent variables of this study were utilization of BSE, mammography, and PS tests. For the evalua- 
tion of these variables, the participants were asked three questions: (i) "How often do you practice BSE?" (ii) "When was the last time you had a MS?" and (iii) "When was the last time you had a PS test?" Those who responded negatively to these questions were classified under "never practiced" for question (i) and "never performed" for the questions (ii) and (iii).

Variables defined in literature that were associated with the utilization of early screening methods by women for BC and CC, which included age, $[17,19]$ marital status,[15] education level,[15,20] income level,[17] health coverage status,[19] consulting with a family physician, $[19,21,22]$ having chronic diseases, [23] body mass index (BMI),[24] and health status,[25] were integrated into the present study as independent variables.

In this context, while marital status and availability of health coverage were evaluated in two categories, the variables of education and income level and age were evaluated in four and five categories, respectively. The chronic disease variable was evaluated based on incidence; in other words, an individual diagnosed with one of 19 different chronic diseases within the past 12 months was categorized as "having a chronic disease." The evaluation of the variable of consulting with a family physician was based on the service received: Those who had received at least one health-related service from a family physician over the past 12 months were categorized under "yes." The variable of BMI was evaluated using calculations made on the basis of parameters such as the height and weight of participants, whereby they were categorized into four categories, namely, underweight $\left(<18.49 \mathrm{~kg} / \mathrm{m}^{2}\right)$, normal range $\left(18.5-24.99 \mathrm{~kg} / \mathrm{m}^{2}\right)$, overweight $\left(25-29.99 \mathrm{~kg} / \mathrm{m}^{2}\right)$, and obese $\left(>30 \mathrm{~kg} / \mathrm{m}^{2}\right)$. To evaluate the variable of general health status, the question "How is your health in general?" was posed to participants, and the findings were categorized into two groups, "good" and "bad."

\section{Analysis of Data}

The data obtained in the Turkey Health Survey 2014 were analyzed through descriptive statistics (frequency and percentage) and besides Chi-square test to ascertain whether the practices of early screening methods for cancer by women showed a difference with respect to their personal features. SPSS (Version 23.0) program was used to process the related analysis. The alpha level was accepted as 0.05 in statistical tests.

\section{Results}

The descriptive findings show that $52.3 \%$ of the women who participated in the study were aged 45 and over. While, of these women, $77 \%$ were married, $51.2 \%$ were primary school graduates, and $53.5 \%$ had an income of $1550 €$ and below. As for the health coverage status, $94.3 \%$ had health coverage. A total of $75.6 \%$ of the participating women had a chronic disease, and $87.6 \%$ visited a family physician for consultation at least once over the past 12 months. A total of $64.3 \%$ of the participants were classified as overweight or obese based on their BMI. With regard to their health status, 55.4\% expressed having bad health. The results also indicated that while $46.5 \%$ of the women practiced BSE, $32.4 \%$ and $35.4 \%$ had MS and PS tests at least once, respectively (Table 1).

Table 2 reveals that the participants in the age groups of 35-44 (51.8\%) and 45-54 (53.3\%) practiced BSE more frequently than those in other age groups; the rate of BSE practice was lowest in women aged 65 and over (29.5\%). The study also found that the practice of BSE among married women (48.6\%) was higher than among single women (39.4\%). This higher utilization rate was also seen among the following: Those with an undergraduate and/or a graduate degree (61.8\%), those with an income of 3181t and over $(60.9 \%)$, those who visited a family physician at least once for consultation (48.1\%), those who were overweight $(46.8 \%)$ or obese $(48.2 \%)$, and those with a good health status (50.4\%).

Table 3 reveals that the participants in the age groups of 45-54 (49.0\%) and 55-64 (48.4\%) had MS more than those in other age groups. The table also shows that married women had MS at a higher rate (33.2\%) than single participants $(29.6 \%)$. This higher utilization rate was also seen among the following: Those with primary education (34.7\%), those with an income of 3181€ and over (39.2\%), those having health coverage (32.9\%), those with a chronic disease $(35.8 \%)$, those who consulted with a family physician at least once $(33.5 \%)$, those who were overweight $(34.7 \%)$ or obese $(39.5 \%)$, those with bad health status (37.7\%), and those who practiced BSE (46.8\%).

Table 4 reveals that the participants in the age groups of 35-44 (39.3\%) and 45-54 (46.5\%) had a higher rate of PS tests than those in other age groups; this rate was lowest in women aged 65 and over (23.1\%). The study findings further indicate that married women had a higher rate of PS tests (38.4\%) than single participants (25.1\%). This higher utilization rate of PS tests was also 
Table 1 Descriptive characteristics of the participants

\begin{tabular}{|c|c|c|}
\hline & $\mathbf{n}$ & $\%$ \\
\hline \multicolumn{3}{|l|}{ Age } \\
\hline $25-34$ & 2003 & 23.3 \\
\hline $35-44$ & 2102 & 24.4 \\
\hline $45-54$ & 1791 & 20.8 \\
\hline $55-64$ & 1325 & 15.4 \\
\hline $65+$ & 1385 & 16.1 \\
\hline \multicolumn{3}{|l|}{ Marital status } \\
\hline Married & 6630 & 77.0 \\
\hline Single & 1976 & 23.0 \\
\hline \multicolumn{3}{|l|}{ Education level } \\
\hline No education & 2173 & 25.2 \\
\hline Primary school & 4424 & 51.2 \\
\hline High school and/or 2-year degree & 1329 & 15.4 \\
\hline Undergraduate and/or graduate degree & 680 & 7.9 \\
\hline \multicolumn{3}{|l|}{ Income level* } \\
\hline $0-1550 €$ & 4603 & 53.5 \\
\hline 1551-2170も & 1349 & 15.7 \\
\hline 2171-3180も & 1357 & 15.8 \\
\hline$\geq 3181 €$ & 1297 & 15.1 \\
\hline \multicolumn{3}{|l|}{ Health coverage status } \\
\hline Have & 8114 & 94.3 \\
\hline Not have & 492 & 5.7 \\
\hline \multicolumn{3}{|l|}{ Having a chronic disease } \\
\hline Have & 6503 & 75.6 \\
\hline Not have & 2103 & 24.4 \\
\hline \multicolumn{3}{|l|}{ Consulting with a family physician } \\
\hline Yes & 7535 & 87.6 \\
\hline No & 1071 & 12.4 \\
\hline \multicolumn{3}{|l|}{ Body mass index } \\
\hline Underweight & 192 & 2.2 \\
\hline Normal range & 2878 & 33.4 \\
\hline Overweight & 2946 & 34.2 \\
\hline Obese & 2590 & 30.1 \\
\hline \multicolumn{3}{|l|}{ Health status } \\
\hline Good & 3834 & 44.6 \\
\hline Bad & 4772 & 55.4 \\
\hline \multicolumn{3}{|l|}{ Breast self-examination } \\
\hline Practice & 3998 & 46.5 \\
\hline Not practice & 4608 & 53.5 \\
\hline \multicolumn{3}{|l|}{ Mammography } \\
\hline Performed & 2787 & 32.4 \\
\hline Not performed & 5819 & 67.6 \\
\hline \multicolumn{3}{|l|}{ Pap smear } \\
\hline Performed & 3044 & 35.4 \\
\hline Not performed & 5562 & 64.6 \\
\hline Total & 8606 & 100 \\
\hline
\end{tabular}

*1 USD=2.188* in 2014

seen among the following: Those with an undergraduate and/or graduate degree (46.8\%), those with an income of $3181 \mathrm{t}$ and over (51.2\%), those with health coverage
(35.7\%), those with a chronic disease (37.0\%), those who consulted with a family physician at least once (36.4\%), those who were overweight (36.7\%) or obese (37.8\%), and those with bad health status (37.0\%).

\section{Discussion}

This study aimed to investigate the utilization of early screening methods (BSE, MS, and PS tests) for BC and CCs by women aged 25 years and above living in Turkey from a perspective based on several factors. The results indicate that while $46.5 \%$ of women practice BSE, $32.4 \%$ have undergone MS and $35.4 \%$ have taken a PS test at least once. Previous research performed in several provinces in Turkey has found that BSE practice rates vary between $27.7 \%$ and $66.5 \%$, MS vary between $7.3 \%$ and $55.9 \%$, and PS tests vary between $23.7 \%$ and $55.9 \%$.[15-17,26,27]

The results demonstrated that married, middleaged women who had an undergraduate and/or graduate degree with an income of 3181t and over, who received health-care services from a family physician at least once, whose BMI was classified as overweight or obese, and who expressed having a good health status practiced a higher rate of BSE than did others. These results concerning BSE practice are similar to findings of previous research.[17,20,21,25] Women with lower education are less knowledgeable about health risks and less informed about screening. For this reason, it is expected finding that woman with higher education levels are more likely to apply to BSE. It is observed that the possibility of using screening methods is low in cases where access to health services is limited.[20] In Turkey, the high of access to primary health care and having information and follow-up program about BC screening methods in primary health-care services is seen important factor that increases BSE.

The results concerning women's rates of utilization of MS show that married, middle-aged women, with primary level education, an income of 3181t and over, who had health coverage, who had received health-care services from a family physician at least once, whose BMI was classified as overweight or obese, and who expressed having bad health status had higher rates of MS than others. These results on mammography utilization correspond to the findings of the previous studies. $[4,22,24]$ Having health insurance is one of the important factors affecting the benefit of women from health services,[15] and studies show that uninsured women are less likely to have MS and PS compared to insured women due to their high cost.[28] For this rea- 
Table 2 Factors associated with practice BSE

\begin{tabular}{|c|c|c|c|c|c|}
\hline \multirow[t]{2}{*}{ Variables } & \multicolumn{2}{|c|}{$\begin{array}{l}\text { Practice } \\
(n=3998)\end{array}$} & \multicolumn{2}{|c|}{$\begin{array}{l}\text { Not practice } \\
(n=4608)\end{array}$} & \multirow[t]{2}{*}{$x^{2} / p$} \\
\hline & $\mathbf{n}$ & $\%$ & $\mathbf{n}$ & $\%$ & \\
\hline \multicolumn{6}{|l|}{ Age } \\
\hline $25-34$ & 921 & 46.0 & 1082 & 54.0 & $x^{2}=219.101$ \\
\hline $35-44$ & 1088 & 51.8 & 1014 & 48.2 & $\mathrm{p}<0.001$ \\
\hline $45-54$ & 955 & 53.3 & 836 & 46.7 & \\
\hline $55-64$ & 626 & 47.2 & 699 & 52.8 & \\
\hline $65+$ & 408 & 29.5 & 977 & 70.5 & \\
\hline \multicolumn{6}{|l|}{ Marital status } \\
\hline Married & 3219 & 48.6 & 3411 & 51.4 & $X^{2}=51.002$ \\
\hline Single & 779 & 39.4 & 1197 & 60.6 & $\mathrm{p}<0.001$ \\
\hline \multicolumn{6}{|l|}{ Education level } \\
\hline No education & 550 & 25.3 & 1623 & 74.7 & $x^{2}=581.876$ \\
\hline Primary school & 2229 & 50.4 & 2195 & 49.6 & $\mathrm{p}<0.001$ \\
\hline High school and/or 2-year degree & 799 & 60.1 & 530 & 39.9 & \\
\hline Undergraduate and/or graduate degree & 420 & 61.8 & 260 & 38.2 & \\
\hline \multicolumn{6}{|l|}{ Income level* } \\
\hline $0-1550 €$ & 1799 & 39.1 & 2804 & 60.9 & $x^{2}=249.666$ \\
\hline 1551-2170も & 671 & 49.7 & 678 & 50.3 & $\mathrm{p}<0.001$ \\
\hline 2171-3180t & 738 & 54.4 & 619 & 45.6 & \\
\hline$\geq 3181 €$ & 790 & 60.9 & 507 & 39.1 & \\
\hline \multicolumn{6}{|l|}{ Consulting with a family physician } \\
\hline Yes & 3621 & 48.1 & 3914 & 51.9 & $x^{2}=62.296$ \\
\hline No & 377 & 35.2 & 694 & 64.8 & $\mathrm{p}<0.001$ \\
\hline \multicolumn{6}{|l|}{ Body mass index } \\
\hline Underweight & 80 & 41.7 & 112 & 58.3 & $x^{2}=8.834$ \\
\hline Normal range & 1292 & 44.9 & 1586 & 55.1 & $\mathrm{p}<0.05$ \\
\hline Overweight & 1378 & 46.8 & 1568 & 53.2 & \\
\hline Obese & 1248 & 48.2 & 1342 & 51.8 & \\
\hline \multicolumn{6}{|l|}{ Health status } \\
\hline Good & 1932 & 50.4 & 1902 & 49.6 & $x^{2}=43.048$ \\
\hline Bad & 2066 & 43.3 & 2706 & 56.7 & $\mathrm{p}<0.001$ \\
\hline
\end{tabular}

*1 USD $=2.188 €$ in 2014. BSE: Breast self-examination

son, it can be said that women with health insurance have a high rate of MS. Due to the impact of cancer screening program in primary health-care services in Turkey, visiting the family doctor is one of the factors that increase the use of MS.

The results concerning women's rates of utilization of PS tests show that married women in the 45-54 age group, with a higher level of education, an income of 3181 t and over, health coverage status, having a chronic disease, who had received health-care services from a family physician at least once, whose BMI was classified as overweight or obese, and who expressed having bad health status, had a higher rate of PS tests than others. These results correspond to the findings of previous research.[15,19,23,24] Woman having a chronic dis- ease, whose BMI was classified as overweight or obese, and who expressed having bad health status needs for doctor consultation. This may indicate that women with more medical conditions are more likely to visit doctors and therefore more likely to be screened. It is observed that women whose BMI was classified as overweight or obese have high rates of using screening methods (SBE, MS, and PS tests) than other. Obese individuals consume more fat, and excessive intake of any kind of fat increases the risk of cancer formation. [29] For this reason, it is expected finding that woman with high BMI have a higher rate of testing than others.

The results of this study appear that self-reported good health was positively associated with BSE practice but negatively associated with utilization of mammog- 


\begin{tabular}{|c|c|c|c|c|c|}
\hline \multirow[t]{2}{*}{ Variables } & \multicolumn{2}{|c|}{$\begin{array}{l}\text { Performed } \\
(n=2787)\end{array}$} & \multicolumn{2}{|c|}{$\begin{array}{l}\text { Not performed } \\
\quad(n=5819)\end{array}$} & \multirow[t]{2}{*}{$x^{2} / p$} \\
\hline & $n$ & $\%$ & $n$ & $\%$ & \\
\hline \multicolumn{6}{|l|}{ Age } \\
\hline $25-34$ & 293 & 14.6 & 710 & 85.4 & $X^{2}=709.606$ \\
\hline $35-44$ & 544 & 25.9 & 1558 & 74.1 & $\mathrm{p}<0.001$ \\
\hline $45-54$ & 877 & 49.0 & 914 & 51.0 & \\
\hline $55-64$ & 641 & 48.4 & 684 & 51.6 & \\
\hline $65+$ & 432 & 31.2 & 953 & 68.8 & \\
\hline \multicolumn{6}{|l|}{ Marital status } \\
\hline Married & 2203 & 33.2 & 4427 & 66.8 & $x^{2}=9.380$ \\
\hline Single & 584 & 29.6 & 1392 & 70.4 & $p=0.002$ \\
\hline \multicolumn{6}{|l|}{ Education level } \\
\hline No education & 612 & 28.2 & 1561 & 71.8 & $x^{2}=34.618$ \\
\hline Primary school & 1537 & 34.7 & 2887 & 65.3 & $p<0.001$ \\
\hline High school and/or 2-year degree & 445 & 33.5 & 884 & 66.5 & \\
\hline Undergraduate and/or graduate degree & 193 & 28.4 & 487 & 71.6 & \\
\hline \multicolumn{6}{|l|}{ Income level* } \\
\hline $0-1550 €$ & 1324 & 28.8 & 3279 & 71.2 & $x^{2}=68.760$ \\
\hline 1551-2170も & 454 & 33.7 & 895 & 66.3 & $\mathrm{p}<0.001$ \\
\hline 2171-3180も & 500 & 36.8 & 857 & 63.2 & \\
\hline$\geq 3181 €$ & 509 & 39.2 & 788 & 60.8 & \\
\hline \multicolumn{6}{|l|}{ Health coverage status } \\
\hline Have & 2668 & 32.9 & 5446 & 67.1 & $X^{2}=16.014$ \\
\hline Not have & 119 & 24.2 & 373 & 75.8 & $\mathrm{p}<0.001$ \\
\hline \multicolumn{6}{|l|}{ Having a chronic disease } \\
\hline Have & 2328 & 35.8 & 4175 & 64.2 & $X^{2}=141.691$ \\
\hline Not have & 459 & 21.8 & 1644 & 78.2 & $\mathrm{p}<0.001$ \\
\hline \multicolumn{6}{|l|}{ Consulting with a family physician } \\
\hline Yes & 2521 & 33.5 & 5014 & 66.5 & $x^{2}=31.825$ \\
\hline No & 266 & 24.8 & 805 & 75.2 & $\mathrm{p}<0.001$ \\
\hline \multicolumn{6}{|l|}{ Body mass index } \\
\hline Underweight & 40 & 20.8 & 152 & 79.2 & $X^{2}=163.115$ \\
\hline Normal range & 702 & 24.4 & 2176 & 75.6 & $\mathrm{p}<0.001$ \\
\hline Overweight & 1021 & 34.7 & 1925 & 65.3 & \\
\hline Obese & 1024 & 39.5 & 1566 & 60.5 & \\
\hline \multicolumn{6}{|l|}{ Health status } \\
\hline Good & 986 & 25.7 & 2848 & 74.3 & $X^{2}=140.361$ \\
\hline Bad & 1801 & 37.7 & 2971 & 62.3 & $p<0.001$ \\
\hline \multicolumn{6}{|l|}{ BSE } \\
\hline Yes & 1870 & 46.8 & 2128 & 53.2 & $X^{2}=706.009$ \\
\hline No & 917 & 19.9 & 3691 & 80.1 & $p<0.001$ \\
\hline
\end{tabular}

*1 USD $=2.188$ in 2014. BSE: Breast self-examination

raphy or Pap testing. This situation can be explained by the trend, need, and possibility factors in the health services usage behavior model developed by Andersen. [30] People who evaluate their perceived health status as good and therefore do not feel any discomfort prefer BSE method without going to a health institution, however, when there is a deterioration in health, peo- ple can use health services to use screening methods to find out where this problem is caused.

\section{Limitations of the Study}

This study has several limitations. First of all, this study was carried out using the data of Turkey Health Survey 2014 and there could be other factors that might be as- 
Table 4 Factors associated with having Pap smear test

\begin{tabular}{|c|c|c|c|c|c|}
\hline \multirow[t]{2}{*}{ Variables } & \multicolumn{2}{|c|}{$\begin{array}{c}\text { Performed } \\
(n=3044)\end{array}$} & \multicolumn{2}{|c|}{$\begin{array}{l}\text { Not performed } \\
\qquad(n=5562)\end{array}$} & \multirow[t]{2}{*}{$x^{2} / p$} \\
\hline & $\mathbf{n}$ & $\%$ & $\mathbf{n}$ & $\%$ & \\
\hline \multicolumn{6}{|l|}{ Age } \\
\hline $25-34$ & 565 & 28.2 & 1438 & 71.8 & $X^{2}=250.118$ \\
\hline $35-44$ & 827 & 39.3 & 1275 & 60.7 & $\mathrm{p}<0.001$ \\
\hline $45-54$ & 832 & 46.5 & 959 & 53.5 & \\
\hline $55-64$ & 500 & 37.7 & 825 & 62.3 & \\
\hline $65+$ & 320 & 23.1 & 1065 & 76.9 & \\
\hline \multicolumn{6}{|l|}{ Marital status } \\
\hline Married & 2549 & 38.4 & 4081 & 61.6 & $x^{2}=119.500$ \\
\hline Single & 495 & 25.1 & 1481 & 74.9 & $p<0.001$ \\
\hline \multicolumn{6}{|l|}{ Education level } \\
\hline No education & 482 & 22.2 & 1691 & 77.8 & $X^{2}=259.803$ \\
\hline Primary school & 1653 & 37.4 & 2771 & 62.6 & $\mathrm{p}<0.001$ \\
\hline High school and/or 2-year degree & 591 & 44.5 & 738 & 55.5 & \\
\hline Undergraduate and/or graduate degree & 318 & 46.8 & 362 & 53.2 & \\
\hline \multicolumn{6}{|l|}{ Income level* } \\
\hline 0-1550も & 1294 & 28.1 & 3309 & 71.9 & $x^{2}=277.200$ \\
\hline 1551-2170も & 523 & 38.8 & 826 & 61.2 & $\mathrm{p}<0.001$ \\
\hline 2171-3180も & 563 & 41.5 & 794 & 58.5 & \\
\hline$\geq 3181 €$ & 664 & 51.2 & 633 & 48.8 & \\
\hline \multicolumn{6}{|l|}{ Health coverage status } \\
\hline Have & 2898 & 35.7 & 5216 & 64.3 & $x^{2}=7.406$ \\
\hline Not have & 146 & 29.7 & 346 & 70.3 & $p=0.007$ \\
\hline \multicolumn{6}{|l|}{ Having a chronic disease } \\
\hline Have & 2409 & 37.0 & 4094 & 63.0 & $x^{2}=32.613$ \\
\hline Not have & 635 & 30.2 & 1468 & 69.8 & $\mathrm{p}<0.001$ \\
\hline \multicolumn{6}{|l|}{ Consulting with a family physician } \\
\hline Yes & 2741 & 36.4 & 4794 & 63.6 & $x^{2}=26.818$ \\
\hline No & 303 & 28.3 & 768 & 71.7 & $\mathrm{p}<0.001$ \\
\hline \multicolumn{6}{|l|}{ Body mass index } \\
\hline Underweight & 57 & 29.7 & 135 & 70.3 & $x^{2}=25.120$ \\
\hline Normal range & 925 & 32.1 & 1953 & 67.9 & $\mathrm{p}<0.001$ \\
\hline Overweight & 1082 & 36.7 & 1864 & 63.3 & \\
\hline Obese & 980 & 37.8 & 1610 & 62.2 & \\
\hline \multicolumn{6}{|l|}{ Health status } \\
\hline Good & 1279 & 33.4 & 2555 & 66.6 & $x^{2}=12.235$ \\
\hline Bad & 1765 & 37.0 & 3007 & 63.0 & $\mathrm{p}<0.001$ \\
\hline
\end{tabular}

*1 USD $=2.188 €$ in 2014

sociated with the use of early screening methods, such as living in rural or urban area, knowledge about cancer screening. These variables may also be included in future studies. Data on use of early screening methods were self-reported, which might lead to underreporting.

\section{Conclusion}

The study investigates the BSE practice rates, mammography, and PS performing rates and it is found that the low number of women using screening methods is alarming and suggests that awareness about screening should be increased. Further the study determines whether there is a difference in these rates with respect to several personal features. It is found that there is a relationship between certain personal features of women - such as age, marital status, education and income level, health coverage status, having a chronic disease, having consulted a family physician, and health status and their utilization of early screening methods for BC 
and CC. The results of the study suggest that certain improvements should be made in various fields to allow intervention to increase the utilization rates of early screening methods of women. The study found that women who consult a family physician have higher rates in terms of utilization of early screening methods. However, the lack of an obligatory referral system in Turkey prompts people to directly apply to hospitals. In this respect, it is believed that the provision of information and guidance concerning screening methods by family physicians is of great importance to educate women about cancer screening. It can be said that the results can be generalized across the country, as the research data are obtained from a sample of women across the country.

Acknowledgments: The authors thank Turkish Statistical Institute for giving necessary permissions to use the data of Turkey Health Survey 2014.

The authors also thank Hacettepe University Technopolis Technology Transfer Center for editing the study in English.

Peer-review: Externally peer-reviewed.

Conflict of Interest: All authors declared no conflict of interest.

Ethics Committee Approval: This study was carried out over existing data and it does not require any human/animal subjects to acquire an ethical approval.

Financial Support: This study has received no financial support.

Authorship contributions: Concept - D.Ü., S.K., İ.B., O.I., Ö.U.; Design - D.Ü., S.K., İ.B., O.I., Ö.U.; Supervision - D.Ü., S.K., İ.B., O.I., Ö.U.; Funding - None; Materials - None; Data collection and/or processing - D.Ü., S.K., İ.B.; Data analysis and/or interpretation - D.Ü., S.K., O.I., Ö.U.; Literature search - D.Ü., S.K., İ.B.; Writing - D.Ü., S.K., İ.B., O.I., Ö.U.; Critical review - D.Ü., S.K., İ.B., O.I., Ö.U.

\section{References}

1. GLOBOCAN. The Global Cancer Observatory; 2020. Available from: https://www.gco.iarc.fr [Last accessed on 2020 Jul 22].

2. Bruni L, Albero G, Serrano B, Mena M, Gómez D, Muñoz J, et al. ICO/IARC Information Centre on HPV and Cancer (HPV Information Centre). Human Papillomavirus and Related Diseases in Turkey, Summary Report; 2019.

3. Avci IA. Factors associated with breast self-examination practices and beliefs in female workers at a Muslim community. Eur J Oncol Nurs 2008;12(2):127-33.
4. Couture MC, Nguyen CT, Alvarado BE, Velasquez LD, Zunzunegui MV. Inequalities in breast and cervical cancer screening among urban Mexican women. Prev Med 2008;47(5):471-6.

5. World Health Organization. WHO Positon Paper on Mammography Screening. Geneva: World Health Organization; 2014. Available from: https://www.apps. who.int/iris/bitstream/handle/10665/137339/?sequence $=1$ [Last accessed on 2021 Aug 01].

6. OECD, Health Statistics; 2020. Available from: https:// www.stats.oecd.org [Last accessed on 2020 Jul 19].

7. Turkey Public Health Institution, National Cancer Screening Standards; 2020. Available from: https:// www.hsgm.saglik.gov.tr/tr/kanser-anasayfa [Last accessed on $2020 \mathrm{Jul} 20$ ].

8. Gupta R, Gupta S, Mehrotra R, Sodhani P. Risk factors of breast cancer and breast self-examination in early detection: Systematic review of awareness among Indian women in community and health care professionals. J Public Health 2020;42(1):118-31.

9. Koç G, Gulen-Savas H, Ergol S, Yildirim-Cetinkaya M, Aydin N. Female university students' knowledge and practice of breast self-examination in turkey. Niger J Clin Pract 2019;22(3):410-5.

10. Brennan M, French J, Houssami N, Kirk J, Boyages J. Breast cancer in young women. Aust Fam Physician 2005;34(10):851-4.

11. Turkey Public Health Institution. Turkish Cancer Statistics. Ankara, Turkey: Turkey Public Health Institution; 2017.

12. Aç1kgöz A, Ergör G. Cervical cancer risk levels in turkey and compliance to the national cervical cancer screening standard. Asian Pac J Cancer Prev 2011;12(4):923-7.

13. Krueger H, Kwon J, Sadownik L, Ogilvie G, Martin RE. What is the most appropriate age to start screening women for cervical cancer? BC Med J 2013;55(6):2826.

14. Turkish Statistical Institute (TURKSTAT). Marriage and Divorce Statistics 2019; 2020. Available from: http://www.tuik.gov.tr/start.do [Last accessed on 2020 Jul 20].

15. Acikgöz A, Çehreli R, Ellidokuz H. Women's knowledge and attitude about cancer and the behaviour for early diagnosis procedures. J Dokuz Eylul Univ Med Sch 2011;25(3):145-4.

16. Ozdemir O, Bilgili N. Knowledge and practices of nurses working in an education hospital on early diagnosis of breast and cervix cancers. TAF Prev Med Bull 2010;9(6):605-12.

17. Secginli S, Nahcivan NO. Factors associated with breast cancer screening behaviors in a sample of Turkish women: A questionnaire survey. Int J Nurs Stud 2006;43(2):161-71. 
18. Turkish Statistical Institute (TURKSTAT), Turkey Health Survey 2014; 2014.

19. Hewitt M, Devesa SS, Breen N. Cervical cancer screening among US women: Analyses of the 2000 national health interview survey. Prev Med 2004;39(2):270-8.

20. Al Nsour M, Brown DW, Tarawneh M, Haddadin R, Walk $\mathrm{H}$. Breast and cervical cancer screening among women in Jordan: Findings from the behavioural risk factor surveillance system-2007. Open Breast Cancer J 2012;4:1-7.

21. Parsa P, Kandiah M, Parsa N. Factors associated with breast self-examination among Malaysian women teachers. East Mediterr Health J 2011;17(6):509-6.

22. Peppercorn J, Houck K, Beri N, Villagra V, Wogu AF, Lyman GH, et al. Breast cancer screening utilization and understanding of current guidelines among rural US women with private insurance. Breast Cancer Res Treat 2015;153(3):659-67.

23. Wu ZH, Black SA, Markides KS. Prevalence and associated factors of cancer screening: Why are so many older Mexican American women never screened? Prev Med 2001;33(4):268-73.

24. Miller S, Rafanan L, Keihany S, Reyes-Ortiz CA. The relationship between body mass index and cancer screening utilization among older women in Latin American and Caribbean cities. J Women Aging
2015;27(1):3-16

25. Hyun MY, Song HJ, Lee EJ, Hong SC, Kim SY, Lee CH. Predictors of breast self examination practice among North Korean immigrant women. Korean J Health Promot 2015;15(1):9-15.

26. Ceber E, Yücel U, Mermer G, Ozentürk G. Health beliefs and breast self-examination in a sample of Turkish women academicians in a university. Asian Pac J Cancer Prev 2009;10(2):213-8.

27. Göçgeldi E, Açıkel CH, Hasde M, Aygut G, Çelik S, Gündüz İ, et al. Investigation of attitudes and behaviors of a group of women who reside at in Ankara Gölbaşı on self-breast examination. Firat Med J 2008;13(4):261-5.

28. Pagán JA, Puig A, Soldo BJ. Health insurance coverage and the use of preventive services by Mexican adults. Health Econ 2007;16(12):1359-69.

29. Akal Yildız E. Cancer and Nutrition, Ministry of Health of the Republic of Turkey. Public Health Agency of Turkey, Department for Obesity, Diabetes and Metabolic Diseases, Ankara; 2012.

30. Andersen R. A Behavioral Model of Families' Use of Health Services, Research Series \#25. Chicago: The University of Chicago, Center for Health Administration Studies; 1968. 